\title{
APLIKASI SUMBANGAN PEMBINAAN PENDIDIKAN SMK BINA PANGUDI LUHUR BERBASIS JAVA NETBEANS
}

\author{
Marno' $^{1}$ V.H Valentino ${ }^{2}$, Rosdiana $^{3}$ \\ 1,2,3 Informatika, Fakultas Teknik dan Ilmu Komputer, Universitas Indraprasta PGRI \\ Jalan Raya Tengah No 80, Kelurahan Gedong, Pasar Rebo, Jakarta Timur 13760 \\ $\underline{\text { marno2803@gmail.com }}$, v.h.valentino.na70@gmail.com ${ }^{2}, \underline{\text { rosdiana.unindra@gmail.com }}{ }^{3}$
}

\begin{abstract}
ABSTRAK
SMK Bina Pangudi Luhur adalah lembaga yang berdiri dalam dunia pendidikan. Beralamat di Jalan Kramat Asem Raya No. 54, Utan Kayu Selatan, Matraman, Jakarta Timur. SMK Bina Pangudi Luhur berdiri sejak Tanggal 27 November 1989. Dunia pendidikan merupakan sebuah bagian yang tidak bisa terpisahkan dari kehidupan bermasyarakat pada umumnya. Pendidikan memang selalu identik dengan proses belajar mengajar, karena hal tersebut memang merupakan kegiatan utama dalam dunia pendidikan. Namun di samping kegiatan belajar mengajar ada banyak hal yang mendukung kelancaran kegiatan tersebut. Salah satunya adalah kegiatan pada bagian administrasi. Tujuan dari penelitian ini adalah untuk mempermudah pekerjaan Staff Tata Usaha pada SMK Bina Pangudi Luhur sehingga dapat dikerjakan secara lebih cepat dan efektif. Pada saat ini sistem yang ada di SMK Bina Pangudi Luhur masih menggunakan cara manual dalam pembuatan laporan dan proses pembayaran. Maka dari itu dengan adanya aplikasi ini dari sistem manual menjadi terkomputerisasi, diharapkan agar sistem pembayaran pada saat ini lebih efektif dan efisien dibandingkan dengan sebelumnya. Peneliti juga melakukan penelitian dengan metode grounded research yaitu metode yang dilakukan berdasarkan fakta yang sebenarnya dan menggunakan analisa perbandingan dengan tujuan mengadakan generalisasi empiris, menetapkan konsep, membuktikan teori, mengembangkan teori, pengumpulan data dan analisa data dalam waktu yang bersamaan. Setelah dilakukan pengujian peneliti menyimpulkan bahwa aplikasi sumbangan pembinaan pendidikan SMK Bina Pangudi Luhur berbasis java netbeans dapat secara efektif dan efisien dalam penyajian data yang cepat dan akurat, Sistem Pembayaran ini tercipta dengan dukungan bahasa pemograman Java Netbeans 8 dan XAMPP.
\end{abstract}

Kata Kunci: Perancangan, Aplikasi, Sekolah, Java Netbeans

\begin{abstract}
SMK Bina Pangudi Luhur is an institution that stands in the world of education. Address at Jalan Kramat Asem Raya No. 54, Utan Kayu Selatan, Matraman, East Jakarta. SMK Bina Pangudi Luhur was established on November 27, 1989. The world of education is an inseparable part of social life in general. Education is always synonymous with the teaching and learning process, because it is the main activity in the world of education. But in addition to teaching and learning activities there are many things that support the smooth running of these activities. One of them is activities in the administration section. The purpose of this study is to facilitate the work of Administrative Staff at SMK Bina Pangudi Luhur so that it can be done more quickly and effectively. At this time the existing system at SMK Bina Pangudi Luhur still uses the manual method in making reports and processing payments. Therefore, with this application from a manual system to a computerized system, it is hoped that the current payment system is more effective and efficient than before. Researchers also conduct research using grounded research method, which is a method based on actual facts and using comparative analysis with the aim of conducting empirical generalizations, establishing concepts, proving theories, developing theories, collecting data and analyzing data at the same time. After testing, the researchers concluded that the application for the education contribution of Bina Pangudi Luhur Vocational High School based on Java Netbeans can effectively and efficiently present data quickly and accurately. This Payment System was created with the support of the Java Netbeans 8 and XAMPP programming languages.
\end{abstract}

Key Word: Design, Application, School, Java Netbeans

\section{PENDAHULUAN}

Perkembagan teknologi dan kebutuhan akan informasi yang semakin meningkat saat ini, tentu saja memerlukan sebuah pelayanan akan pengolahan data yang sangat cepat dan tepat, saat ini tekhnologi dapat menyajikan semua informasi yaitu informasi yang relevan, akurat dan tepat waktu yang dapat digunakan untuk keperluan pribadi, bisnis, dan pemerintahan (Riwayadi, 2013). Dengan melihat perkembangan teknologi yang semakin maju penulis mencoba untuk 
membantu permasalahan yang sering terjadi, penulis melihat pada SMK Bina Pangudi Luhur yang memiliki kelemahan dalam adminstrasi. Hal ini dikarenakan dalam pengolahan data yang digunakan masih manual sehingga masih banyak masalah yang di hadapi seperti pemborosan waktu, tenaga, dan uang untuk penggandaan laporan atau untuk keperluan lainnya. Oleh karena itu penulis ingin membuatkan solusi untuk menangani permasalahan itu. Supaya pembayaran biaya sekolah ini, dapat memperlancar kinerja pembelajaran dan menyediakan fasilitas-fasilitas yang di perlukan oleh para siswa. Adapun tujuan penelitian ini adalah Merancang sebuah aplikasi Sumbangan Pembinaan Pendidikan SMK Bina Pangudi Luhur Berbasis Java Netbeans untuk mencapai hasil yang cepat, tepat dan akurat serta digunakan secara berkelanjutan (Ramadhan, 2020). Mengurangi tingkat kesalahan penginputan data dan pengecekan data dan dapat membantu dalam pembuatan aplikasi Sumbangan Pembinaan Pendidikan SMK Bina Pangudi Luhur Berbasis Java Netbeans sehingga menghasilkan informasi yang akurat (Fathansyah, 2012).

Dalam rangka mendapatkan hasil penelitian yang baik, selain melakukan penelitian secara langsung peneliti juga melakukan kajian pustaka. Dari hasil yang telah dilakukan, salah satu hasil penelitian yang jadi acuan adalah: Penelitian dari (Winni, Fitri Wulan Sari, 2017)yang berjudul "Perancangan Sistem Informasi Pembayaran SPP pada SMA Kemala Bhayangkari Kubu Raya" Pada sistem informasi yang sedang berjalan proses pencatatan data SPP siswa masing mengacu pada dokumen yang masih berupa berkas atau arsip-arsip dan belum memiliki media penyimpanan yang tepat. Setiap siswa/murid diwajibkan untuk membayar SPP (Sumbangan Pembinaan Pendidikan), yang dimana SPP adalah sejumlah biaya yang dibebankan kepada siswa/murid untuk membantu lembaga pendidikan memperlancar proses belajar mengajar. Besarnya sumbangan pembinaan pendidikan di Sma Kemala Bhayangkari Kubu Raya perkelas tidaklah sama. Besarnya SPP di sekolah negeri yang dikelola oleh pemerintah dengan yang di kelola swasta umumnya berbeda. SPP yang wajib di bayar siswa dan di sekolah swasta biasanya lebih besar dari pada SPP sekolah negeri. Hal ini lantaran sekolah swasta membiayai penyelenggaraan pendidikannya dari SPP saja dan dari yayasan, sedangkan sekolah negeri mendapat bantuan dari pemerintah. Dengan adanya sistem informasi ini diharapkan dapat membantu aktifitas sekolah terutama di bagian administrasi dalam mengetahui pembayaran SPP dan juga menyajikannya ke dalam bentuk laporan pembayaran SPP dengan cepat, mudah, dan akurat (Saragih, 2017).

\section{METODE PENELITIAN}

Metode penelitian yang digunakan dalam penelitian ini adalah metode Grounded Research, yaitu suatu metode penelitian yang berdasarkan pada fakta yang menggunakan analisis perbandingan dengan tujuan untuk mengadakan generalisasi empiris, menetapkan konsep, mengembangkan teori, pengumpulan dan analisis data dalam waktu yang bersamaan (Nazir, 2011). Maksudnya adalah penulis langsung datang ke tempat penelitian untuk mancari informasi mengenai data dan permasalahan yang ada. Dari data tersebut penulis nantinya akan menggunakan data tersebut sebagai teori. Setelah menentukan masalah yang ingin diselidiki, mengumpulkan data atau informasi yang ada dilapangan, menganalisis dan menjelaskan masalah yang ditemukan serta membuat laporan hasil penelititian (Riwayadi, 2013).

\section{HASIL DAN PEMBAHASAN}

Berdasarkan masalah-masalah yang dihadapi pada SMK Bina Pangudi Luhur maka peneliti membuat sebuah Aplikasi Sumbangan Pembinaan Pendidikan SMK Bina Pangudi Luhur yang tujuannya supaya dalam pencatatan yang sebelumnya dilakukan secara manual menjadi komputerisasi, yang hasilnya akan optimal dan sangat meghemat waktu dan pelaporannya juga lebih mudah dan efisien.

\section{Diagram Konteks}

Menurut Jogiyanto (2002:714), "Diagram konteks merupakan sebuah diagram sederhana yang menggambarkan hubungan antara entity luar, masukan data dan keluar dari sistem" (Jogiyanto H. , Dasar ilmu komputerpemrogaman sistem informasi dan integrasi buatan, 2002). 


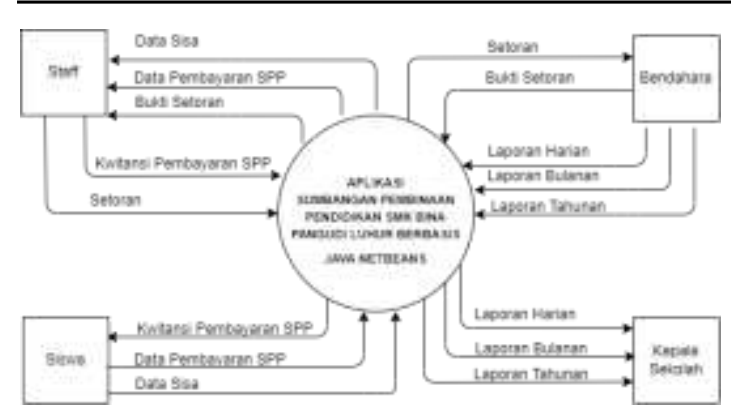

Gambar 1. Diagram Konteks

\section{Use Case Diagram Yang Diusulkan}

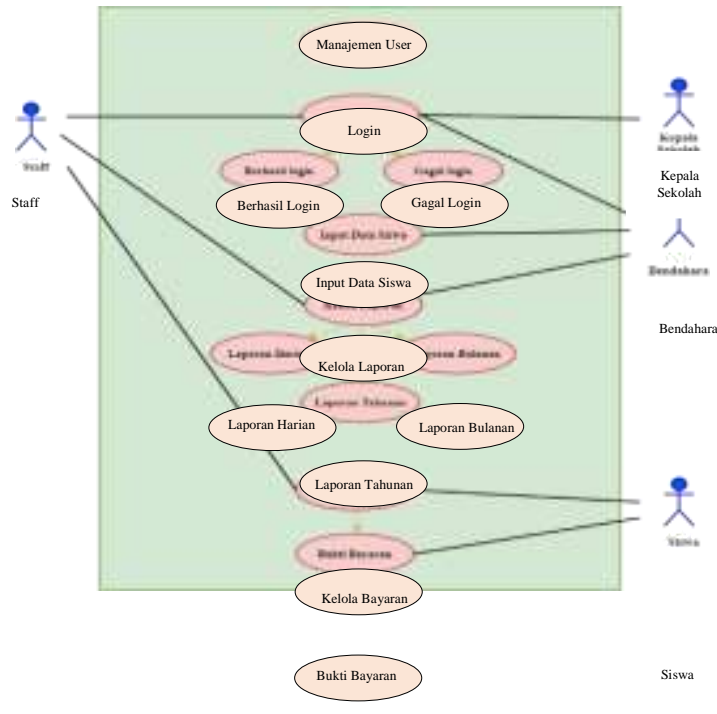

Gambar 2. Use Case Diagram

Pada diagram use case diatas memperlihatkan gambaran umum dari Perancangan sistem informasi pembayaran SPP pada SMK Bina Pangudi Luhur yang dimana petugas sebagai Staff dan Bendahara untuk melakukan pengolahan data pembayaran SPP seperti pengolahan data user, data siswa, pembayaran SPP, laporan harian, laporan bulanan dan laporan tahunan (Ndoili, 2016).

\section{Tampilan Layar Sistem}

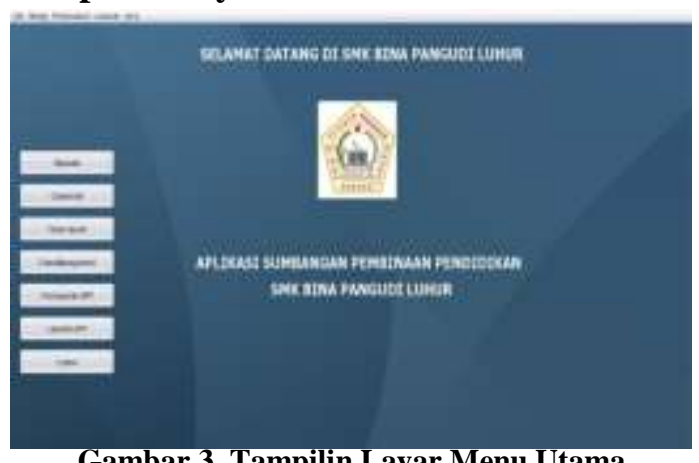

Gambar 3. Tampilin Layar Menu Utama

Layar diatas menampilkan tampilan Menu Utama pada Aplikasi Sumbangan Pembinaan
Pendidikan SMK Bina Pangudi Luhur, pada layar utama tersedia menu bar yang digunakan untuk memasukan data yang berkaitan dengan data siswa, data kelas, data tahun ajaran, data pembayaran SPP, dan laporan.

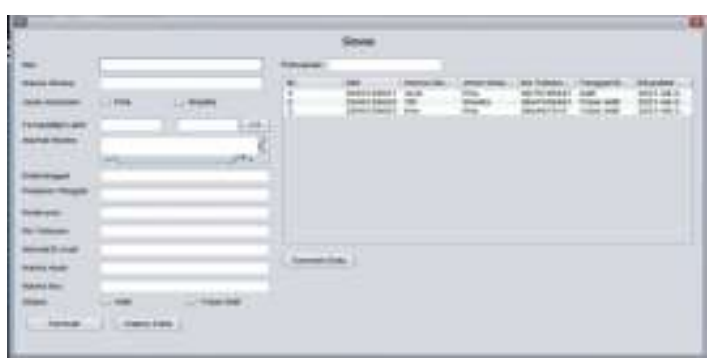

Gambar 4. Tampilan data siswa

Layar diatas menampilkan tampilan form data siswa, dimana pada tampilan tersebut admin menginput semua data siswa mulai dari nis, nama siswa, tempat tanggal lahir, dan seterusnya (Ramadhan, 2020)

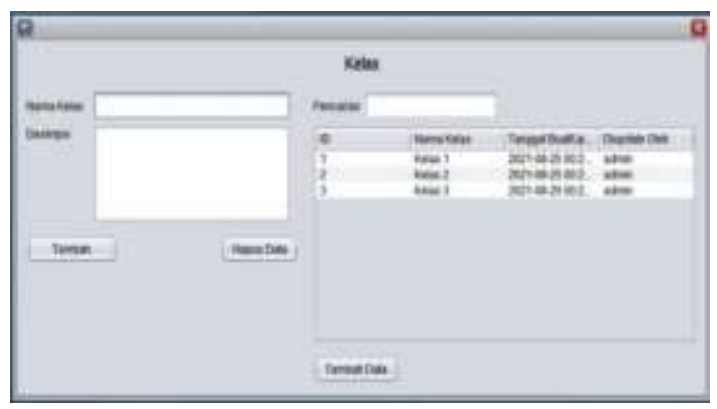

Gambar 5. Tampilan kelas

Layar diatas menampilkan tampilan form pembuatan kelas, untuk membuat beberapa kelas yang ada pada SMK Bina Pangudi Luhur dari kelas X, XI dan XII.

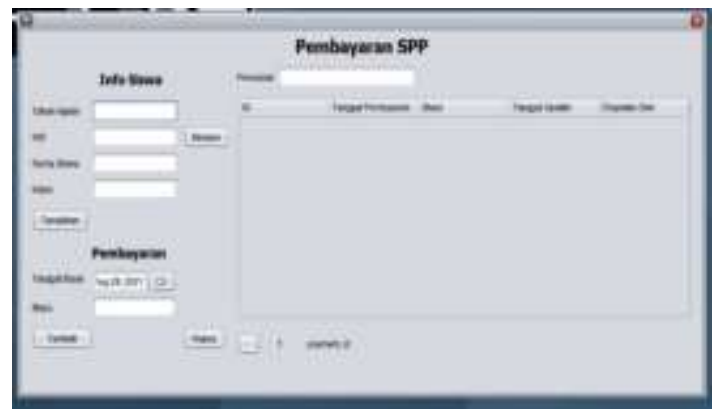

Gambar 6. Tampilan pembayaran

Layar diatas menampilkan tampilan form pembayaran, petugas menginput data pembayaran dari siswa yang nantinya akan dilaporkan kepada bendahara

1148 | Aplikasi Sumbangan Pembinaan Pendidikan SMK Bina Pangudi Luhur Berbasis Java Neatbeans 


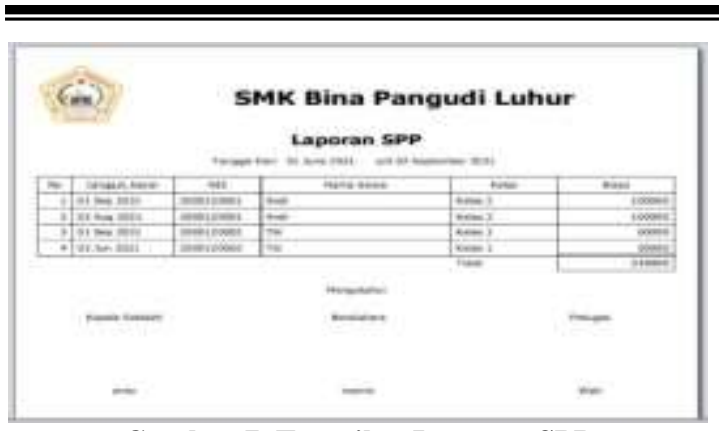

Gambar 7. Tampilan Laporan SPP

Pada Layar di atas menampilkan laopran pembayaran SPP. Petugas mencetak laporan pembayaran lalu menyerahkan kepada bendahara untuk ditandangani (Suwardi, 2020)

\section{SIMPULAN DAN SARAN}

Dari hasil pembahasan yang telah diuraikan pada bab-bab sebelumnya, maka dapat disimpulkan bahwa dengan adanya Aplikasi Sumbangan Pembinaan Pendidikan SMK Bina Pangudi Luhur ini diharapkan dapat membantu kinerja SMK Bina Pangudi Luhur agar lebih efisien dan akurat dalam hal pengolahan data. Perancangan sistem informasi pembayaran spp ini dibuat dengan menggunakan bahasa pemrograman Java NetBeans dengan database MySQL. Mempermudah admin dalam hal pelayanan kepada siswa dengan adanya program sistem ini. Aplikasi Sumbangan Pembinaan Pendidikan SMK Bina Pangudi Luhur ini dapat meminimalisir adanya kesalahan pencatatan data dan data yang disimpan lebih terstruktur dan juga lebih aman.

\section{Daftar Pustaka}

Enterprise, J. (2015). Mengenal Java dan Database Dengan Netbeans. Elex Media Komputindo.

Fathansyah. (2012). Basis Data. Bandung: Informatika.

Jogiyanto, H.M, 2002, Dasar Ilmu Komputer Pemrogaman Sistem Informasi dan Integrasi Buatan, Andi, Yogyakarta.

Lnu, W. (2020). Materi 3-Use Case Diagram. Nazir. (2011). Metode Penelitian. Yogyakarta: Buku Beta.

Ndoili, G. D. (2016). Ta: Rancang Bangun Aplikasi Keuangan Siswa Pada Sma Kemala Bhayangkari 3 Porong (Doctoral Dissertation, Institut Bisnis Dan Informatika Stikom Surabaya).
Riwayadi, P. (2013). Pemanfaatan Perkembangan Teknologi Informasi Dan Komunikasi Untuk Kemajuan Pendidikan Di Indonesia. Available At Pls-Um Database.

Ramadhan, D. (2020). Perancangan Sistem Aplikasi Pembayaran Pada SMPI AlHasyimiyah Berbasis Java Netbeans. Jurnal Riset dan Aplikasi Mahasiswa Informatika (JRAMI), 1(03)

Saragih, H., Marbun, J. P., \& Pasaribu, D. (2017). Perancangan Sistem Informasi Penerimaan Kas Dan Pengeluaran Kas Pada Pt. Medan Media Grafikatama Tanjung Morawa. Methomika: Jurnal Manajemen Informatika \& Komputerisasi Akuntansi, 1(1), 28-32.

Suwardi, S., Suprapti, S., \& Danang, D. (2020). Manajemen Pengolahan Data Administrasi Keuangan Sekolah Menggunakan Metode Grounded Research. E-Bisnis: Jurnal Ilmiah Ekonomi Dan Bisnis, 13(2), 8-16.

Sutabri, Tata. (2012). Analisis Sistem Informasi. Yogyakarta: Andi.

Winni, Fitri Wulan Sari. 2017. "Perancangan Sistem Informasi Pembayaran Spp Pada Sma Kemala Bhayangkara Kubu Raya”. Amik BSI, Pontianak. 